\title{
Influence of vacuum annealing on structures and properties of Al-Ti-Si-N coatings with corrosion resistance
}

\author{
Mohan Chen, Fei Cai, Wanglin Chen, Qimin Wang, Shihong Zhang *
}

School of Materials Science and Engineering, Anhui University of Technology, Maanshan City, Anhui Province 243002, PR China.

*Corresponding author: Tel \& Fax number: +86-555-3553789; Email address: tougaoyouxiang206@163.com

\begin{abstract}
The corrosion behaviors in $10 \mathrm{wt} \% \mathrm{H}_{2} \mathrm{SO}_{4}$ solution of the Al-Ti-Si-N coatings, deposited on $316 \mathrm{~L}$ stainless steel using multi-arc ion plating then vacuum annealed at $700^{\circ} \mathrm{C}$, $800^{\circ} \mathrm{C}$ and $900^{\circ} \mathrm{C}$ for 2 hours, was investigated. The microstructures, compositions and surface morphologies of the coatings were characterized by utilizing X-ray diffraction (XRD), transmission electron microscopy (TEM), X-ray photoelectron spectroscope (XPS) and scanning electron microscope (SEM) analyses. The adhesion strength and corrosion behavior of coatings were measured by scratch test and electrochemical polarization curves, respectively. The results indicated that the as-deposited coatings were mainly comprised of solid solution $(\mathrm{Ti}, \mathrm{Al}) \mathrm{N}$ phase and amorphous $\mathrm{Si}_{3} \mathrm{~N}_{4}$ phase. With increasing annealing temperature, the solid solution gradually decomposed into fcc-TiN and fcc-AlN phases and further into hcp-AlN phase. The defects on coating surface and adhesion strength of coatings were improved simultaneously. The electrochemical results revealed that all coated samples had better corrosion resistance than the substrate, and the coatings annealed at $800^{\circ} \mathrm{C}$ exhibited the best corrosion behavior in acid solutions. This was caused by the formation of amorphous $\mathrm{Si}_{3} \mathrm{~N}_{4}$ phase and anti-corrosion hcp-AlN phase.
\end{abstract}


Keywords: Multi-arc ion plating; Al-Ti-Si-N coating; Vacuum annealing; Corrosion resistance; Stainless steel

\section{Introduction}

During the last few decades, hard coating deposited by physical vapor deposition (PVD) were widely applied in various fields because of their high hardness, improved wear resistance, good oxidation resistance and corrosion resistance [1-4]. The first generation PVD hard coating, such as TiN coatings [5-7], had already exhibited pretty good potential to enhance various properties of substrate material. C. Liu et al. [8] deposited TiN coatings on Ti-6Al-4V substrates using a plasma assisted electron beam PVD technique, and found that the PVD TiN coatings significantly reduced the corrosion rate. R.J. Rodriguez et al. [9] reported a comparative study of the mechanical properties of the most employed hard coatings like TiN, TiCN, TiAlN, $\mathrm{CrN}$ and $\mathrm{ZrN}$, and found that the TiN coatings had the highest hardness among these coatings. But with times past by requirement and development, the first generation PVD coatings like TiN coatings, were not satisfactory for many advanced engineering applications owing to many disadvantages such as defects of coatings produced by PVD technique and limited oxidation resistance at high temperatures [10-13]. These defects could lead to a poor corrosion resistance of TiN coatings by making the corrosive attack of substrate easier, which decreased the lifetime, durability and performance of coatings. To overcome this problem, some elements like aluminum and silicon, were incorporated into TiN coatings to form multi-composite compound coatings such as TiSiN [14-16], TiAlN [11,13,17] and TiAlSiN [18-19] coatings, which significantly improved the hardness, thermal stability, oxidation resistance and corrosion resistance of coatings. TiSiN coatings exhibited superhardness (more than $40 \mathrm{GPa}$ ) due to the presence of amorphous 
matrix of $\mathrm{Si}_{3} \mathrm{~N}_{4}[10,20]$. Incorporation of $\mathrm{Si}$ in TiN coatings could also improve the oxidation resistance at high temperature [21-22].It has been reported that another metal, Al, could be introduced into the TiN coatings to form the TiAlN coatings, which significantly increased the oxidation resistance as well as the mechanical and tribological properties [11,13,23]. It is worth mentioning that the corrosion resistance of TiSiN and TiAlN coatings was both improved compared with the TiN coatings [14-18]. As research continued, much attention has been paid to the AlTiSiN coatings, which could further improve properties of coatings, especially the corrosion resistance of the coatings [24-26]. Y. H. Yoo et al. [27] deposited TiN, TiAlN and TiAlSiN coatings on AISI H13 tool steel substrates by cathodic arc plasma. They found that the TiAlSiN coatings had the lowest current density and the highest protective efficiency which could be attributed to the refinement of microstructure caused by the incorporation of Si. C.-L. Chang et al. [28] reported the microstructure, corrosion and tribological behaviors of TiAlSiN coatings deposited by cathodic arc plasma deposition. The results showed that the TiAlSiN coating exhibited much better mechanical and corrosion resistance than the $\mathrm{TiN}$ and $\mathrm{TiSiN}$ coatings, which could be attributed to the formed nano-composites structure caused by the incorporations of Al and Si. N. D. Nam et al. [29] researched corrosion behavior of TiN, TiAlN, TiAlSiN-coated 316L stainless steel in simulated proton exchange membrane fuel cell (PEMFC) environment and found that the TiAlSiN-coated 316L SS had the highest corrosion resistance. In the meantime, AlTiSiN coatings also presented good oxidation resistance under high temperature [25-27], indicating enormous potential for application at high temperature. However, the research on corrosion resistance of AlTiSiN coatings at high temperature condition was still blank. X.B. Zhao et al. [30] reported the effect of heat treatment on the electrochemical corrosion 
behavior of TiN coatings and pointed out that heat treatment increased the corrosion resistance of the coatings. In our previous work, vacuum annealing also has been proved to enhance the corrosion resistance of other coating [31]. Besides decreasing the residual stress of coatings, the structural evolution and compositional transformation caused by vacuum annealing also played an important role to enhance corrosion resistance of the coating. Thus, it is necessary to investigate the influence of heat treatment on corrosion behavior of Al-Ti-Si-N for understanding the relationship among these factors of Al-Ti-Si-N coating.

In this work, the Al-Ti-Si-N coatings were deposited on 316L SS by multi-arc ion plating (M-AIP). The M-AIP had better deposition efficiency compared with other PVD technologies to obtain hard coating with dense structure, which possessed wider application scope. After that, the coatings were annealed at $700^{\circ} \mathrm{C}, 800^{\circ} \mathrm{C}$ and $900^{\circ} \mathrm{C}$ in vacuum for 2 hours. The effect of annealing on the structures, morphologies, adhesion strength, especially corrosion resistance were investigated and discussed. The corrosion resistance in $10 \mathrm{wt} \% \mathrm{H}_{2} \mathrm{SO}_{4}$ solution to were investigated and discussed in detail.

\section{Experimental details}

\subsection{Test specimen preparation}

The substrate used in this study was mirror polished 316L stainless steel (SS) with 15 $\mathrm{mm}$ in diameter and $3 \mathrm{~mm}$ in thickness. Prior to coating process, the specimens were cleaned in acetone and ethanol using an ultrasonic cleaner for $20 \mathrm{~min}$, respectively. Deposition of Al-Ti-Si-N coatings was carried out using a multi-arc ion plating system with four $\mathrm{Al}_{67} \mathrm{Ti}_{33}$ targets, four $\mathrm{Al}_{60} \mathrm{Ti}_{30} \mathrm{Si}_{10}$ targets and four $\mathrm{Cr}$ targets (99.9\% purity). These targets were symmetrically installed on the opposite of the barrel-shaped vacuum chamber wall and the distance between targets and samples was about $230 \mathrm{~mm}$. Before the beginning of deposition, 
the deposition chamber was evacuated to a base pressure of $4.0 \times 10^{-3} \mathrm{~Pa}$ and heated at temperature of $350{ }^{\circ} \mathrm{C}$. The samples were cleaned by sputtering in argon plasma for $30 \mathrm{~min}$ using a bias voltage of $-1100 \mathrm{~V}$. Then increased the temperature to $450{ }^{\circ} \mathrm{C}$, the $\mathrm{Cr}$ targets were operated for $20 \mathrm{~min}$ to obtain $\mathrm{Cr}$ layer to reinforce adhesion strength (vacuum was $3 \times 10^{-1} \mathrm{~Pa}$, bias voltage was $-800 \mathrm{~V}$, rotation speed was $2 \mathrm{rpm}$ ). For AlTiN interlayer, closed $\mathrm{Cr}$ targets and the $\mathrm{Al}_{67} \mathrm{Ti}_{33}$ targets were opened for 5 min to obtain AlTiN interlayer with thickness of about $10 \mathrm{~nm}$. The nitrogen was operated with partial pressure of $3 \mathrm{~Pa}$ and flow-rate of 900 sccm. After that, kept the partial pressure and the flow-rate of nitrogen, $\mathrm{Al}_{67} \mathrm{Ti}_{33}$ targets and $\mathrm{Al}_{60} \mathrm{Ti}_{30} \mathrm{Si}_{10}$ targets were simultaneously worked for $130 \mathrm{~min}$ to form the Al-Ti-Si-N coatings. After deposition process, the coated samples were vacuum annealed at $700^{\circ} \mathrm{C}, 800^{\circ} \mathrm{C}$ and $900^{\circ} \mathrm{C}$ under vacuum of $7.5 \times 10^{-2} \mathrm{~Pa}$ for 2 hours. After annealing, the samples were cooled to room temperature in the furnace to prevent oxidation.

\subsection{Structural characterization}

The crystalline structure of coatings was analyzed by a Bruker D8.advance X-ray diffractometer $(\mathrm{Cu}-\mathrm{K \alpha}, 50 \mathrm{kV}$ and $100 \mathrm{~mA})$. The scan rate was $2^{\circ} / \mathrm{min}$ from $30^{\circ}$ to $90^{\circ}$ in standard $2 \theta-\theta$ mode. The microstructure of coatings were investigated by high resolution transmission electron microscopy (HRTEM). X-ray photoelectron spectroscopy (XPS, Thermo ESCALAB250) with an Al-Ka $(\mathrm{h} v=1486.6 \mathrm{eV})$ radiation source operated at $150 \mathrm{~W}$ was performed to observe the bonding states of the coatings. The XPS spectra were obtained after plasma cleaning by in situ sputtering with Ar+ ions and calibrated using carbon peak $\mathrm{C}$ 1s at $284.8 \mathrm{eV}$. Scanning electron microscopy (SEM) was used to observe the morphologies of coatings. The adhesion strength of coatings was measured using a scratch tester.

\subsection{Electrochemical measurements}


The corrosion behavior of the coatings was investigated by electrochemical tests in $10 \mathrm{wt} \% \mathrm{H}_{2} \mathrm{SO}_{4}$ solution at room temperature (The coating is intended for application field of PEMFC, the $10 \mathrm{wt} \% \mathrm{H}_{2} \mathrm{SO}_{4}$ solution is similar to the PEMFC corrosive medium) using a potentiostat Model CHI604D. A conventional three-electrode system was used including a working electrode of $1.0 \mathrm{~cm}^{2}$, a platinum counter electrode of $1.0 \mathrm{~cm}^{2}$ as auxiliary electrode and a saturated calomel electrode ( $\mathrm{SCE}$, saturated $\mathrm{KCl}$ ) as a reference electrode. The scanning rate of potentiodynamic test was $1 \mathrm{mV} \mathrm{s}^{-1}$. The corrosion current density ( $\mathrm{i}_{\text {corr }}$ ) and corrosion potential $\left(\mathrm{E}_{\mathrm{corr}}\right)$ were obtained by the intersection of the extrapolation of cathodic and anodic Tafel curves. The cathodic Tafel $\left(\beta_{\mathrm{c}}\right)$, anodic Tafel $\left(\beta_{\mathrm{a}}\right)$ and polarization resistance $\left(\mathrm{R}_{\mathrm{p}}\right)$ were calculated by the CHI604D software. Each series of the samples were measured 3 times in corrosion tests to avoid errors. Before potentiodynamic test, the open circuit potential was applied for 1 hour to stabilize all of the samples.

\section{Results and discussion}

\subsection{Phase structure}

XRD patterns of the Al-Ti-Si-N coatings before and after vacuum annealing are shown in Fig.1. They show that the as-deposited coating was mainly composed of ( $\mathrm{Ti}, \mathrm{Al}) \mathrm{N}$ solid solution. After $700^{\circ} \mathrm{C}$ annealing, the AlN phases with face-centered cubic structure (fcc) appeared due to the solid solution decomposition. With further increasing the annealing temperature, the (Ti,Al)N and fcc-AlN diffraction peaks gradually became less intense while the TiN phases were detected. It could be concluded that (Ti,Al)N decomposed into TiN and AlN. It is worth noting that no peaks of Si element or silicon compounds could be found in XRD patterns of the Al-Ti-Si-N coatings, which revealed that Si element probably existed in the form of amorphous phase, which were in accordance with the following analysis of high 
resolution transmission electron microscopes (HRTEM) of coatings.

Fig. 2 shows the Al 2p, Ti 2p, Si 2p, N1s and O 1s XPS spectra of Al-Ti-Si-N coatings after $800^{\circ} \mathrm{C}$ vacuum annealing. As shown in Fig.2a (Al 2p photoelectron peak region), the peaks located at $73.3 \mathrm{eV}, 73.7 \mathrm{eV}, 74.1 \mathrm{ev}$ and $74.49 \mathrm{eV}$ corresponded to the $\mathrm{AlN}, \mathrm{Al}_{2} \mathrm{TiO}_{5}$ and $\mathrm{Al}_{2} \mathrm{O}_{3}$, respectively. Fig.2b shows the Ti $2 \mathrm{p}$ photoelectron peak region, which is composed of Ti 2 p3/2 and Ti 2p1/2 peaks by spin-orbit interactions. The peaks with binding energies of $455.1 \mathrm{eV}$ and $455.78 \mathrm{eV}$ were recognized as $\mathrm{TiN}$, the peaks centred at $456.8 \mathrm{eV}$ and $457.8 \mathrm{eV}$ recognized as titanium oxides, which were the photoelectron peak of $\mathrm{Ti} 2 \mathrm{p} 3 / 2$; the peaks located at binding energies of $455.78 \mathrm{eV}$ and $462 \mathrm{eV}$ were the photoelectron peak of Ti 2p1/2, which presented the same chemical bond states as Ti $2 \mathrm{p} 3 / 2$; The Si $2 \mathrm{p}$ photoelectron peak region indicated that its bonding energies mainly corresponded to $\mathrm{Si}_{3} \mathrm{~N}_{4}$ according to Fig.2c, which also can be proved in following TEM analysis. For the $\mathrm{N} 1 \mathrm{~s}$ photoelectron peak region shown in Fig. 2d, the peaks located at $96.9 \mathrm{eV}$ and $397.3 \mathrm{eV}$ corresponded to TiN and AlN, respectively, which can also be seen in TEM in that next chapter. Fig.2e shows the photoelectron peak region of $\mathrm{O} 1 \mathrm{~s}$, the fitted results showed that the $\mathrm{O}$ element mainly existed in aluminum oxides, titanium oxides and silicon oxides, indicating that a little oxide formed during vacuum annealing.

\subsection{Microstructure}

Fig.3 shows the TEM micrographs of the as-deposited Al-Ti-Si-N coatings. The Al-Ti-Si-N layer exhibited local superlattice microstructure with a modulation period of about 15.7nm as shown in Fig.3a. The coatings were mainly composed of fcc-TiN and hcp-AlN phases based on the selected area electron diffraction (SAED) pattern in Fig.3b, and the diffraction lightspots were dispersive, meaning the coatings had low crystallinity. Fig.3c 
presents the high resolution TEM (HRTEM) of coatings. It could be found that some nano-particles with the grain size of 1-6 nm were embedded in the amorphous phases. The XPS results confirmed that the amorphous phase were $\mathrm{Si}_{3} \mathrm{~N}_{4}$. Fig.3d is the HRTEM of particle (red elliptical area) in Fig.3c, the interplanar spacing $d$ of the particles was $0.212 \mathrm{~nm}$, which was consistent with the $\{111\}$ TiN phase, indicating that these nano-particles were TiN phases. Also in reference [26], a small amount of hcp-AlN was reported to exist in amorphous phase based on the HRTEM image analysis. A. Flink et al. [26] studied the impact of Si contents on structure and mechanical properties of arc ion plating $\left(\mathrm{Ti}_{0.33} \mathrm{Al}_{0.67}\right)_{1-\mathrm{x}} \mathrm{Si}_{\mathrm{X}} \mathrm{N}$ coatings. They found that, when $\mathrm{x} \leq 0.02$ at. $\%$, metastable state fcc-(Ti, $\mathrm{Al}) \mathrm{N}$ formed in the coatings and $\mathrm{Si}$ contents most gathered at grain boundary of fcc-(Ti,Al)N phases, inhibiting the grain expansion. As Si contents further increased (0.02 at. $\% \leq x \leq 0.17$ at.\%), extra Si facilitated the formation of hcp-(Al,Ti)N phase. When $\mathrm{Si}$ contents were more than 0.17 at.\%, coatings exhibited the amorphous state. In this study, the XPS analysis also confirmed that the Si content of Al-Ti-Si-N coatings was about 2.0 at.\%, which was far more than the reported 0.17 at.\%. Thus, the Al-Ti-Si-N coatings were mainly composed of fcc-(Ti,Al)N, hcp-(Al,Ti)N and amorphous phases, which was consistent with the results from TEM.

Fig.4 shows the HAADF-STEM and SAED patterns of the Al-Ti-Si-N coatings annealed at $800^{\circ} \mathrm{C}$. As shown in Fig.4a, the structure morphologies of annealed samples had no obvious difference compared with the as-deposited sample, which were still composed of adhesive sub-layer, interlayer and Al-Ti-Si-N layer. The adhesive sub-layer exhibited bright white color, which demonstrated an area of heavy atomic number. The interlayer presented dark and light contrast. According to the EDS pattern, dark area mainly consisted of $\mathrm{Al}, \mathrm{N}$ and little Ti elements. It can be concluded that the dark area was mainly composed of hcp-(Al,Ti)N phases 
and the light area were fcc-(Ti,Al)N phases. It has been reported [32-33] that AlTiN coatings decomposed into fcc-TiN and fcc-AlN phases by spinodal decomposition during high temperature annealing, and semi-coherent interface or coherent interface formed among fcc-TiN phase, fcc-AlN phase and c-(Al,Ti)N phase, which enhanced the hardness of coatings. As annealing temperature further increased, metastable fcc-AlN transformed to more stable hcp-AlN, which decreased the hardness of coatings due to broken coherent interface. The SAED pattern of interlayer in Fig.4b confirmed that the solid solution phases were decomposed into AlN and TiN phase due to vacuum annealing.

\subsection{Surface morphology}

Fig.5 shows the surface morphologies and EDS result of the Al-Ti-Si-N coatings before and after vacuum annealing. As shown in Fig.5a, many pits and particles appeared on the surface of the as-deposited sample, which revealed the typical character of M-AIP. These particles can be divided into two categories: "black spots" indicating liquid particles and "white spots" indicating solid particles [34]. These particles were sputtered on the sample surface due to the formation of cathode spots under high power. As shown in Fig.5, the pits on the surface gradually diminished with increasing annealing temperature, during which liquid particles melted caused by high temperature and then the pits were filled. The solid particles became larger but fewer simultaneously. The EDS analysis indicated that these solid particles were of ceramic phase (rich in $\mathrm{Al}$, Ti and $\mathrm{N}$ ), which were hardly melting under $900^{\circ} \mathrm{C}$ but easily aggregated together under high annealing temperature. In general, the number and size of particles and pits gradually decreased with increasing annealing temperature.

\subsection{Adhesion strength}

Fig. 6 presents the scratch test results of the Al-Ti-Si-N coatings before and after vacuum 
annealing. Lc2 was denoted as some small amount of peeling stage and Lc3 was denoted as the complete peeling off stage. Generally, Lc2 corresponded to adhesive failure and was defined as the adhesion strength [35]. In this study, the adhesion strength of the as-deposited coatings was $31.2 \mathrm{~N}$. After $700^{\circ} \mathrm{C}$ annealing, the adhesion strength increased to $38 \mathrm{~N}$. The improved adhesion strength was mainly due to the residual stress release and improvement of surface roughness, and also related to the formation of semi-coherent interface and coherent interface after $700^{\circ} \mathrm{C}$ annealing. However, the Lc2 values of the coatings after $800^{\circ} \mathrm{C}$ and $900^{\circ} \mathrm{C}$ annealing decreased rapidly to $32.8 \mathrm{~N}$ and $23.9 \mathrm{~N}$, respectively. This phenomenon could be explained by the damage of semi-coherent interface and coherent interface due to the fact that the unstable fcc-AlN transformed into the stable hcp-AlN after $800^{\circ} \mathrm{C}$ annealing.

\subsection{Corrosion behavior}

Fig.7 presents the potentiodynamic polarization curves of the Al-Ti-Si-N coatings before and after vacuum annealing in $10 \mathrm{wt} \% \mathrm{H}_{2} \mathrm{SO}_{4}$ solution. As shown in Table.1, the $\mathrm{i}_{\text {corr }}$ of as-deposited Al-Ti-Si-N coating was slightly lower than that $316 \mathrm{~L}$ SS substrate $\left(1.30 \times 10^{-5}\right.$ A.cm ${ }^{-2}$ vs. $7.17 \times 10^{-5}$ A. $\mathrm{cm}^{-2}$ ), indicating that the corrosion resistance of as-deposited sample has no obvious improvement compared with the substrate. The much lower $\mathrm{E}_{\text {corr }}$ also revealed that the as-deposited sample could be corroded much more easily than the substrate $(-0.293 \mathrm{~V}$ vs. $-0.045 \mathrm{~V}$ ). But with the increasing annealing temperature, the $\mathrm{i}_{\text {corr }}$ of coatings were gradually decreased and the $800^{\circ} \mathrm{C}$ annealed coatings had the lowest $\mathrm{i}_{\text {corr }}\left(2.79 \times 10^{-8} \mathrm{~A} . \mathrm{cm}^{-2}\right)$ of all the coated samples, meaning the lowest corrosion rate. The sample annealed at $800^{\circ} \mathrm{C}$ also maintained the highest $\mathrm{E}_{\mathrm{corr}}(0.331 \mathrm{~V})$ and $\mathrm{R}_{\mathrm{p}}\left(1.55 \times 10^{6} \Omega . \mathrm{cm}^{2}\right)$, which provided the coating with a better protection performance. However, there was an interesting phenomenon that was found: the $\mathrm{E}_{\text {corr }}$ and $\mathrm{i}_{\text {corr }}$ of $900^{\circ} \mathrm{C}$ annealed sample became slightly worse compared with the 
$800^{\circ} \mathrm{C}$ annealed samples, but was still better than that of the as-deposited sample and 316 L SS substrate, which showed that the $900^{\circ} \mathrm{C}$ annealed sample remained good corrosion resistance.

Based on previous analysis, the existence of amorphous $\mathrm{Si}_{3} \mathrm{~N}_{4}$ in the coatings and superlattice microstructure of coatings made the as-deposited Al-Ti-Si-N coatings exhibit better corrosion resistance compared with the substrates. After $700^{\circ} \mathrm{C}$ vacuum annealing, fcc-(Ti,Al)N phase of the coatings decomposed into fcc-TiN and fcc-AlN phases by spinodal decomposition. Compared with the solid solution phase, the fcc-TiN phase and the fcc-AlN phase all had good corrosion resistance in $\mathrm{H}_{2} \mathrm{SO}_{4}$ solution [30,36]. Therefore, the corrosion resistance of coatings significantly improved after $700^{\circ} \mathrm{C}$ vacuum annealing. As the annealing temperature increased to $800^{\circ} \mathrm{C}$, unstable fcc-AlN phase transformed into the stable hcp-AlN phase with better corrosion resistance [32-33]. In addition, some $\mathrm{Al}$ atoms combined with $\mathrm{O}$ atoms to form $\mathrm{Al}_{2} \mathrm{O}_{3}$ on the surface of coatings as revealed by the XPS analysis. The formed $\mathrm{Al}_{2} \mathrm{O}_{3}$ could block the path of corrosion medium to the coatings [17,37]. Thus, the coatings after $800^{\circ} \mathrm{C}$ vacuum annealing exhibited excellent corrosion resistance. However, with further increasing annealing temperature to $900^{\circ} \mathrm{C}$, the high energy resulted in the atoms adsorbed on the substrate migrating each other, forming the atomic cluster even crystal nucleus. The grain sizes of these atomic clusters and crystal nucleus constantly increased during $900^{\circ} \mathrm{C}$ annealing process, which decreased the amount of amorphous parts, and enhanced the crystallinity of the coatings, so that these corrosion medium inserted easily into the coatings. Therefore, the corrosion resistance of coatings slightly decreased after $900^{\circ} \mathrm{C}$ vacuum annealing.

\section{Conclusion}

In this study, the microstructures, surface morphologies, adhesion strength and corrosion resistance of the Al-Ti-Si-N coatings, before and after vacuum annealing were investigated. 
The obtained conclusions are as follows:

1. The as-deposited Al-Ti-Si-N coatings were mainly composed of solid solution (Ti,Al)N phase and amorphous $\mathrm{Si}_{3} \mathrm{~N}_{4}$ phase. With increasing annealing temperatures, the (Ti,Al)N phase decomposed into fcc-TiN and fcc-AlN phases by spinodal decomposition. As annealing temperature further increased, unstable fcc-AlN phase transformed into more stable hcp-AlN phase.

2. Many pits and particles were presented on the surface of as-deposited Al-Ti-Si-N coatings, and the number of these defects, especially liquid particles and pits, gradually diminished with increasing annealing temperature,

3. Based on the scratch tests, Al-Ti-Si-N coatings annealed at $700^{\circ} \mathrm{C}$ had the highest adhesion strength of $38 \mathrm{~N}$, and the adhesion strength of coatings gradually decreased with further increasing the annealing temperature. It could be explained by the formed stable hcp-AlN phase, that makes the semi-coherent interface and coherent interface be damaged.

4. Potentiodynamic polarization curves showed that the annealed coated samples had better corrosion resistance than blank substrate and as-deposited sample, and the coating annealed at $800^{\circ} \mathrm{C}$ exhibited the best corrosion resistance performance in $10 \mathrm{wt} \% \mathrm{H}_{2} \mathrm{SO}_{4}$ solutions.

\section{Acknowledgments:}

This work was supported by the National Science Foundation of China (No. 51305002), International Science \& Technology Cooperation Program of China (No. 2014DFG72720) and the Science Foundation of Anhui Province (No. 1408085QE92).

\section{References}

[1] M. Nordin, M. Larsson, S. Hogmark, Mechanical and tribological properties of 
multilayered PVD TiN/CrN, Wear 232(1999) 221-225 .

[2] J. Lin, J. J. Moore, J. Wang, W. D. Sproul, High temperature oxidation behavior of CrN/AlN superlattice films, Thin Solid Films 519 (2011) 2402-2408.

[3] Tomas Polcar, Albano Cavaleiro, High temperature properties of CrAlN, CrAlSiN and AlCrSiN coatings - Structure and oxidation, Mater. Chem. Phys. 129 (2011) 195-201.

[4] A. Thobor-Keck, F. Lapostolle, A.S. Dehlinger, D. Pilloud, J.F. Pierson, C. Coddet, Influence of silicon addition on the oxidation resistance of CrN coatings, Surf. Coat. Technol. 200 (2005) 264-268.

[5] J. Huang, C. Ma, H. Chen, Effect of Ti interlayer on the residual stress and texture development of TiN thin films, Surf. Coat. Technol. 200 (2006) 5937-5945.

[6] R. Morita, K. Azuma, S. Inoue, R. Miyano, H. Takikawa, A. Kobayashi, E. Fujiwara, H. Uchida, M. Yatsuzuka, Corrosion resistance of TiN coatings produced by various dry processes, Surf. Coat. Technol. 136 (2001) 207-210.

[7] J. Chen, G. Yu, J. Huang, Corrosion behavior and adhesion of ion-plated TiN films on AISI 304 steel, Mater. Chem. Phys. 65 (2000) 310-315.

[8] C. Liu, Q. Bi , A. Matthews, Tribological and electrochemical performance of PVD TiN coatings on the femoral head of Ti-6Al-4V artificial hip joints, Surf. Coat. Technol. 163-164 (2003) 597-604.

[9] R.J. Rodriguez, J.A. Garcia, A. Medrano, M. Rico, R. Sanchez, R. Martinez, C. Labrugere, M. Lahaye, A. Guette, Tribological behaviour of hard coatings deposited by arc-evaporation PVD, Vacuum 67 (2002) 559-566.

[10] C. Guo, D. Lee, P. Chen, Deposition of TiSiN coatings by arc ion plating process, Appl. Surf. Sci. 254 (2008) 3130-3136. 
[11] J. Hsieh , C. Liang , C. Yu , W. Wu, Deposition and characterization of TiAlN and multi-layered TiN/TiAlN coatings using unbalanced magnetron sputtering, Surf. Coat. Technol. 108-109 (1998) 132-137.

[12] N. Carvalho, E. Zoestbergen , B. Kooi, J. De Hosson, Stress analysis and microstructure of PVD monolayer TiN and multilayer TiN/(Ti,Al)N coatings, Thin Solid Films 429 (2003) $179-189$.

[13] V.K. Grips, H. C. Barshilia, V. Selvi, Kalavati, K. Rajam, Electrochemical behavior of single layer $\mathrm{CrN}$, TiN, TiAlN coatings and nanolayered TiAlN/CrN multilayer coatings prepared by reactive direct current magnetron sputtering, Thin Solid Films 514 (2006) 204-211.

[14] G. Laudisio, B. Seipel, A. Ruffini, K.G. Nickel, Corrosion behavior of $\mathrm{Si}_{3} \mathrm{~N}_{4}-\mathrm{TiN}$ composite in sulphuric acid, Corros. Sci. 47 (2005) 1666-1677.

[15] M. S. Ahmed, P. Munroe, Z. Jiang, X. Zhao, W. Rickard, Z. Zhou, L. Li, Z. Xie, Corrosion behaviour of nanocomposite TiSiN coatings on steel substrates, Corros. Sci. 53 (2011) 3678-3687.

[16] V. Selvi, V.K. Grips, H. C. Barshilia, Electrochemical behavior of superhard nanocomposite coatings of $\mathrm{TiN} / \mathrm{Si}_{3} \mathrm{~N}_{4}$ prepared by reactive DC unbalanced magnetron sputtering, Surf. Coat. Technol. 224 (2013) 42-48.

[17] R. Ananthakumar, B. Subramanian, Akira Kobayashi, M. Jayachandran, Electrochemical corrosion and materials properties of reactively sputtered TiN/TiAlN multilayer coatings, Ceram. Int. 38 (2012) 477-485.

[18] X. Li, W. Wu, H. Dong, Microstructural characterisation of carbon doped CrAlTiN nanoscale multilayer coatings, Surf. Coat. Technol. 205 (2011) 3251-3259. 
[19] Y. Hwang, D. Lee, High-temperature Oxidation of Nano-multilayered AlTiSiN Thin Films deposited on WC-based carbides, Corros. Sci. Technol. 12 (2013) 119-124.

[20] X. Liu, Y. Ren, X. Tan, S. Sun, E. Westkaemper, The structure of Ti-Si-N superhard nanocomposite coatings: ab initio study, Thin Solid Films 520 (2011) 876-880.

[21] J. Choi , K. Cho , M. Lee , K. Kim, Effects of Si content and free Si on oxidation behavior of Ti-Si-N coating layers, Thin Solid Films 447-448 (2004) 365-370.

[22] L. Chen, B. Yang, Y. Xu, F. Pei, L. Zhou, Y. Du, Improved thermal stability and oxidation resistance of Al-Ti-N coating by Si addition, Thin Solid Films 556 (2014) 369-375.

[23] Y. Chim, X. Ding, X. Zeng, S. Zhang, Oxidation resistance of TiN, CrN, TiAlN and CrAlN coatings deposited by lateral rotating cathode arc, Thin Solid Films 517 (2009) $4845-4849$.

[24] A. Miletić, P. Panjan, B. Škorić, M. Čekada, G. Dražič, J. Kovač, Microstructure and mechanical properties of nanostructured $\mathrm{Ti}-\mathrm{Al}-\mathrm{Si}-\mathrm{N}$ coatings deposited by magnetron sputtering, Surf. Coat. Technol. 241 (2014) 105-111.

[25] A. Vennemann, H. Stock, J. Kohlscheen, S. Rambadt, G. Erkens, Oxidation resistance of titanium-aluminium-silicon nitride coatings, Surf. Coat. Technol. 174-175 (2003) 408-415.

[26] A. Flink, J.M. Andersson, B. Alling, R. Daniel, J. Sjölén, L. Karlsson, L. Hultman, Structure and thermal stability of arc evaporated $\left(\mathrm{Ti}_{0.33} \mathrm{Al}_{0.67}\right)_{1-\mathrm{x}} \mathrm{Si}_{\mathrm{X}} \mathrm{N}$ thin films, Thin Solid Films 517 (2008) 714-721.

[27] Y. Yoo, D. Le, J. Kim, S. Kim, P. Vinh, Corrosion behavior of TiN, TiAlN, TiAlSiN thin films deposited on tool steel in the $3.5 \mathrm{wt} \% \mathrm{NaCl}$ solution, Thin Solid Films 516 (2008) $3544-3548$.

[28] C. Chang, J. Lee, M. Tseng, Microstructure, corrosion and tribological behaviors of 
TiAlSiN coatings deposited by cathodic arc plasma deposition, Thin Solid Films 517 (2009) $5231-5236$.

[29] N. Nam, M. Vaka, N. Hung, Corrosion behavior of TiN, TiAlN, TiAlSiN-coated 316L stainless steel in simulated proton exchange membrane fuel cell environment, J. Power Sources 268 (2014) 240-245.

[30] X. Zhao, D. Yan, S. Li, C. Lu, The effect of heat treatment on the electrochemical corrosion behavior of reactive plasma-sprayed TiN coatings, Appl. Surf. Sci. 257 (2011) $10078-10083$.

[31] M. Chen, W. Chen, F. Cai, S. Zhang, Q. Wang, Structural evolution and electrochemical behaviors of multilayer Al-CrSi-N coatings, Surf. Coat. Technol. 296 (2016) 33-39.

[32] L. Chen, Y. Du, P. H. Mayrhofer, S. Q. Wang, J. Li, The influence of age-hardening on turning and milling performance of Ti-Al-N coated inserts, Surf. Coat. Technol. 202 (2008) $5158-5161$.

[33]A. Horling, L. Hultmana, M. Oden, J. Sjolen, L. Karlsson, Mechanical properties and machining performance of $\mathrm{Ti}_{1-\mathrm{x}} \mathrm{Al}_{\mathrm{x}} \mathrm{N}$-coated cutting tools, Surf. Coat. Technol. 191 (2005) $384-392$.

[34] Q. Wang, K. Kim, Effect of negative bias voltage on CrN films deposited by arc ion plating. II. Film composition, structure, and properties. J. Vac. Sci. Technol. A, 26(2008), 1267-1276.

[35] S. Zhang, L. Wang, Q. Wang, M. Li, A superhard CrAlSiN superlattice coating deposited by multi-arc ion plating: I. Macroparticles filtration and film-growth characteristics, Surf. Coat. Technol. 214 (2013) 160-167.

[36] F. Haftlang, A. Habibolahzadeh, M. H. Sohi, Improving electrochemical properties of 
AISI 1045 steels by duplex surface treatment of plasma nitriding and aluminizing, Appl. Surf. Sci. 329 (2015) 240-247.

[37] A. Ait-Djafer, N. Saoula, H. Aknouche, B. Guedouar, N. Madaoui, Deposition and characterization of titanium aluminum nitride coatings prepared by RF magnetron sputtering, Appl. Surf. Sci. 350 (2015) 6-9. 


\section{Table captions}

Table 1 Potentiodynamic polarization data of the 316L SS and Al-Ti-Si-N coatings before and after vacuum annealing in $10 \mathrm{wt} \% \mathrm{H}_{2} \mathrm{SO}_{4}$ solution.

\section{Figure captions}

Fig.1 The XRD patterns of as-deposited Al-Ti-Si-N coatings and vacuum annealed coatings at temperatures of $700{ }^{\circ} \mathrm{C}, 800{ }^{\circ} \mathrm{C}$ and $900{ }^{\circ} \mathrm{C}$.

Fig. 2 XPS spectra of Al-Ti-Si-N coatings after $800{ }^{\circ} \mathrm{C}$ vacuum annealing: (a) Al 2p (b) Ti $2 p$ (c)Si 2p (d)N 1s (e) O 1s.

Fig.3 The HRTEM images of as-deposited Al-Ti-Si-N coatings:(a) low power TEM image, The SAED pattern in the middle region of the coatings,(c)(d) the HRTEM images.

Fig.4 The cross-sectional structure and SAED pattern of Al-Ti-Si-N coatings annealed at $800^{\circ} \mathrm{C}$

Fig.5 Surface SEM micrographs and EDS of as-deposited Al-Ti-Si-N coatings (a), and coatings after vacuum annealed at temperatures of $700{ }^{\circ} \mathrm{C}(\mathrm{b}), 800{ }^{\circ} \mathrm{C}$ (c) and $900{ }^{\circ} \mathrm{C}$ (d).

Fig.6 Scratch test results for as-deposited Al-Ti-Si-N coatings (a), and coatings after vacuum annealed at temperatures of $700{ }^{\circ} \mathrm{C}(\mathrm{b}), 800^{\circ} \mathrm{C}(\mathrm{c})$ and $900{ }^{\circ} \mathrm{C}(\mathrm{d})$.

Fig.7 Potentiodynamic polarization curves of the Al-Ti-Si-N coatings before and after vacuum annealing in $10 \% \mathrm{H}_{2} \mathrm{SO}_{4}$ solution. 


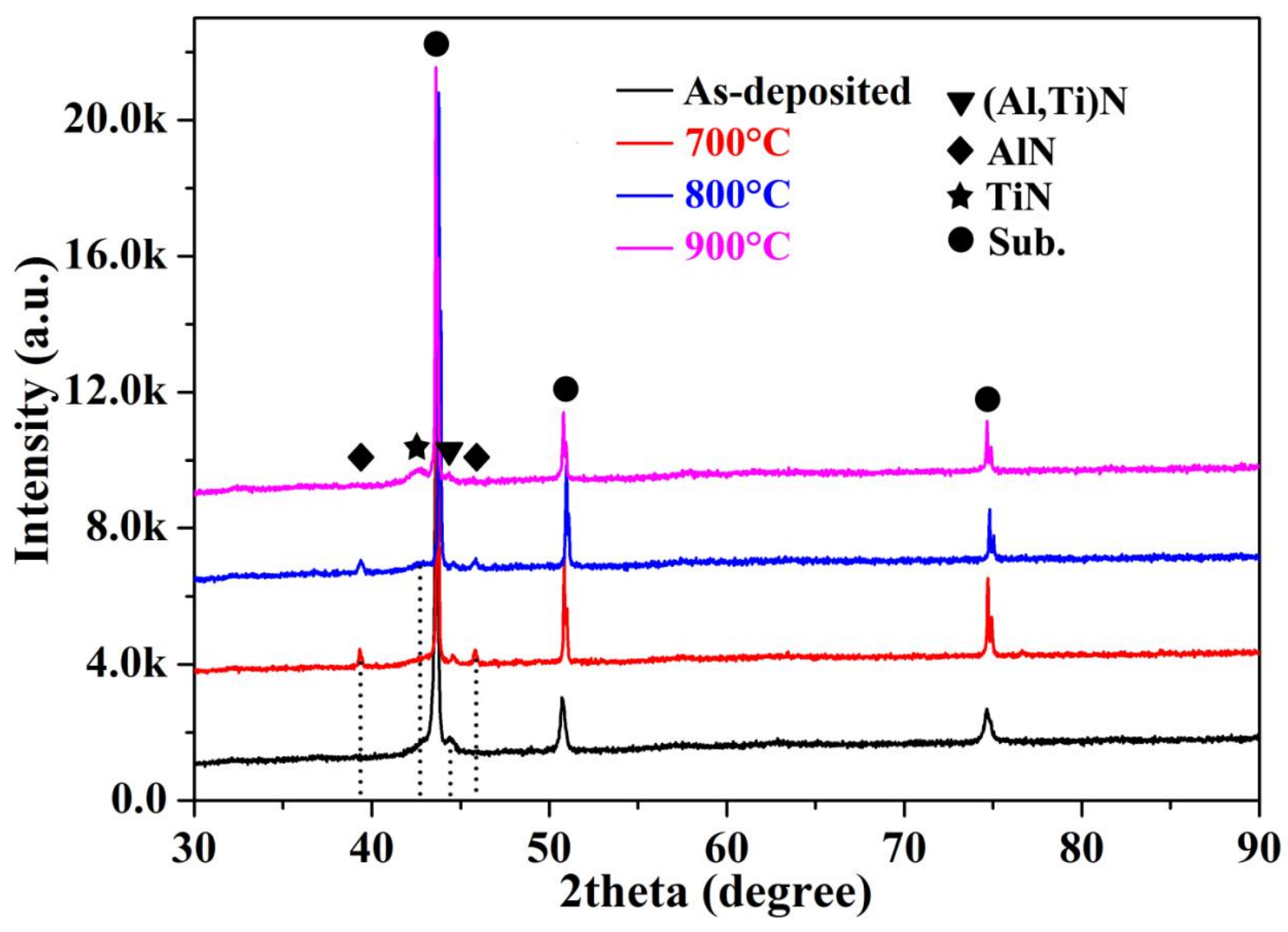



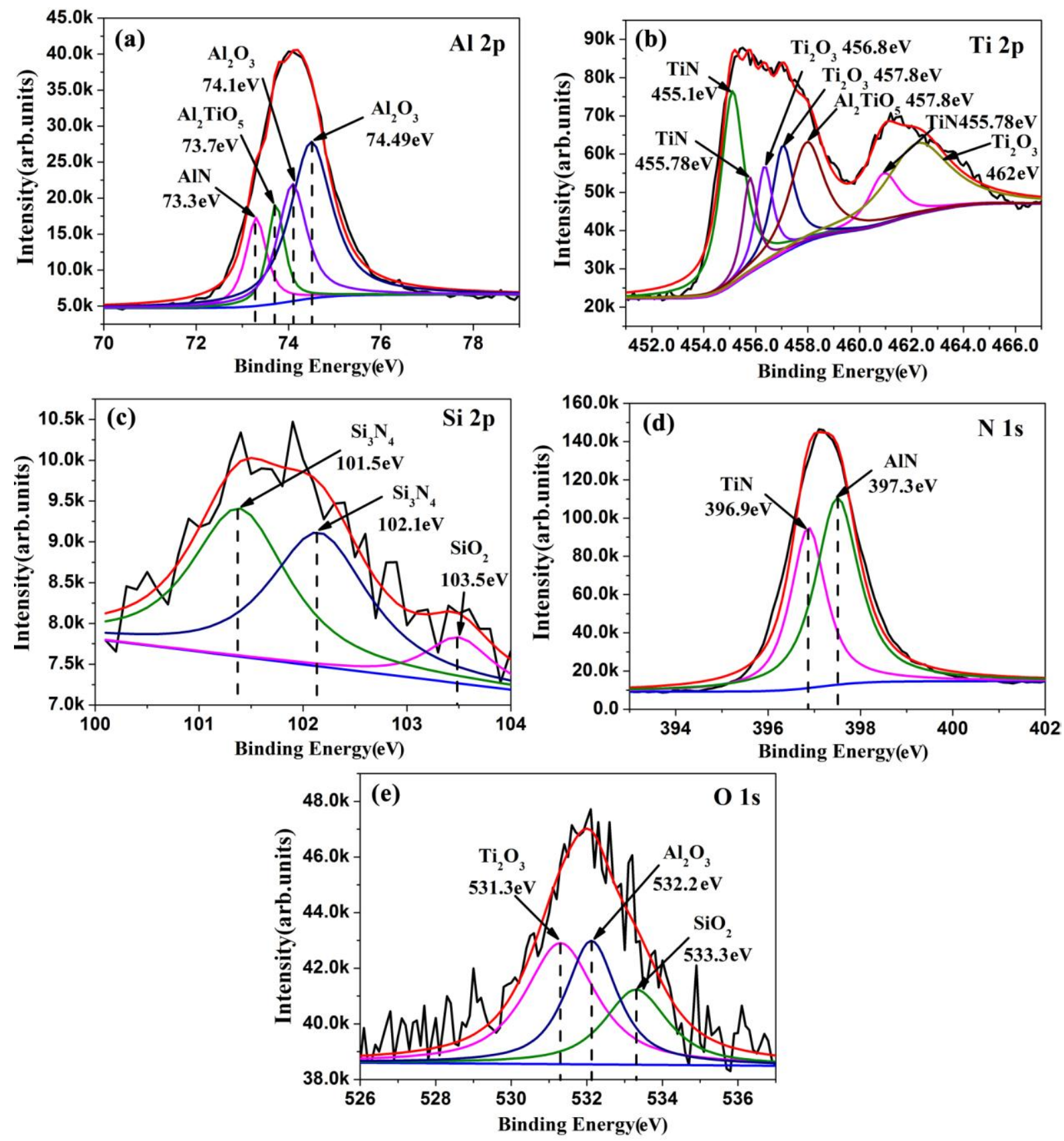


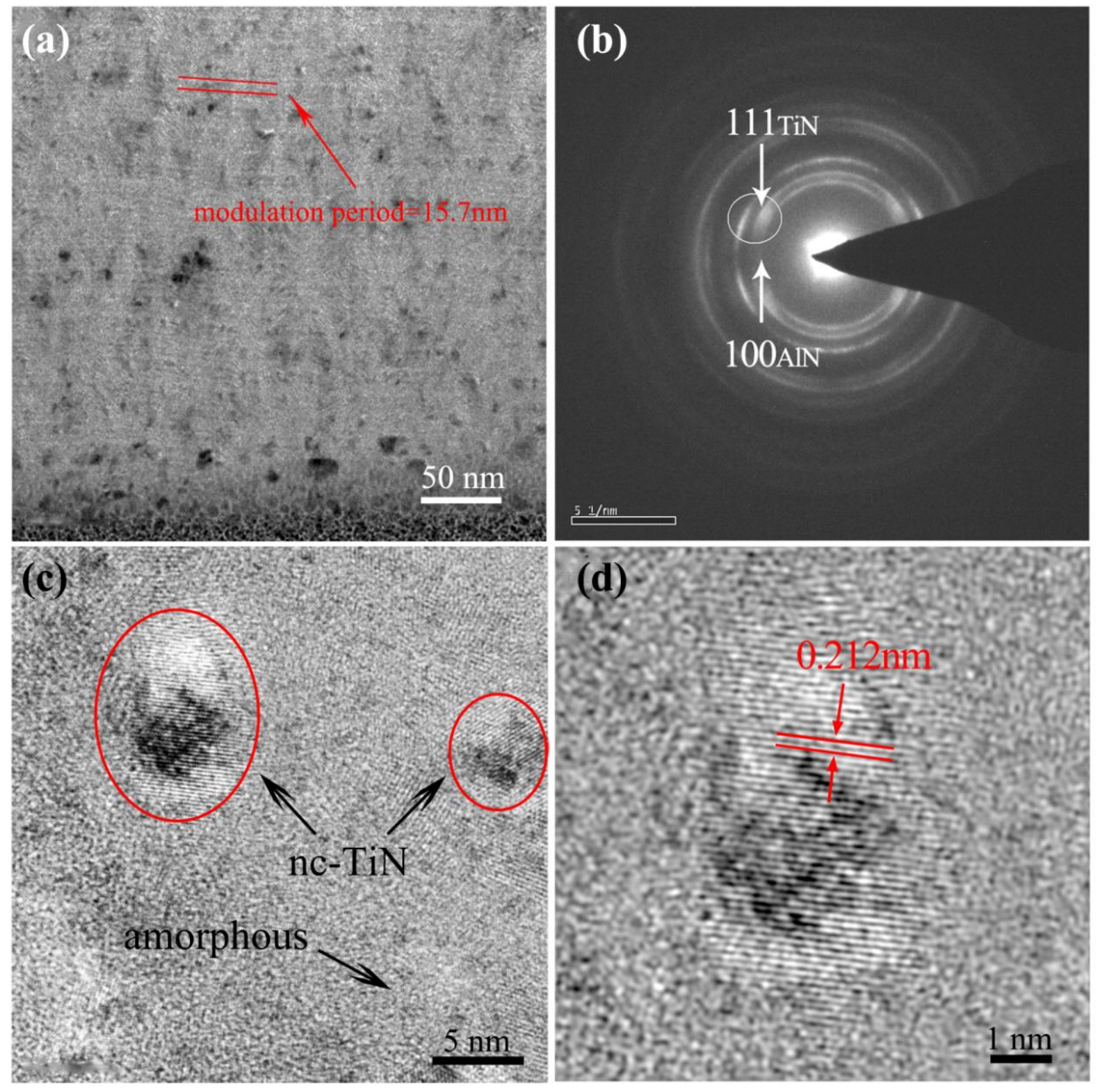




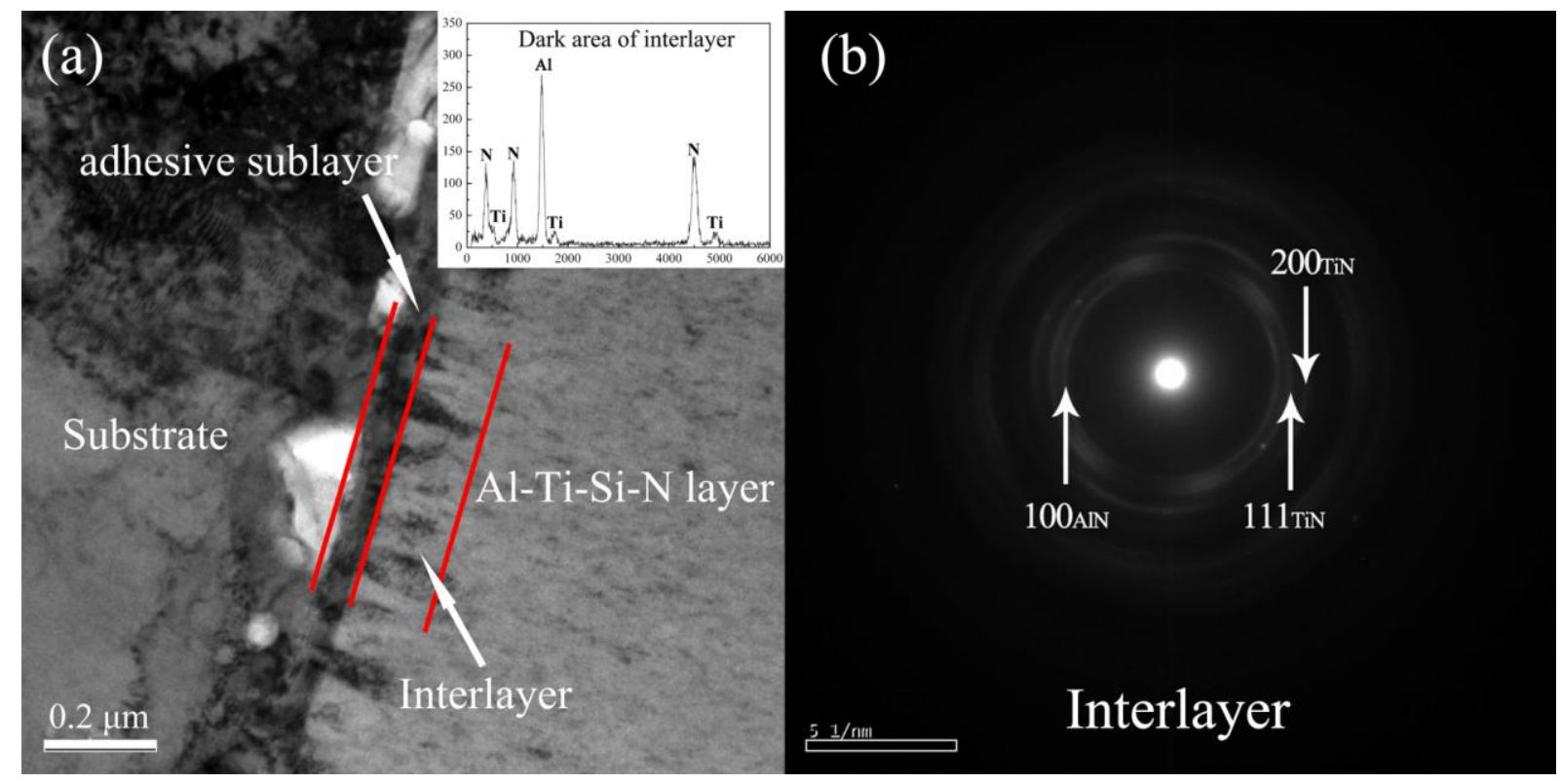




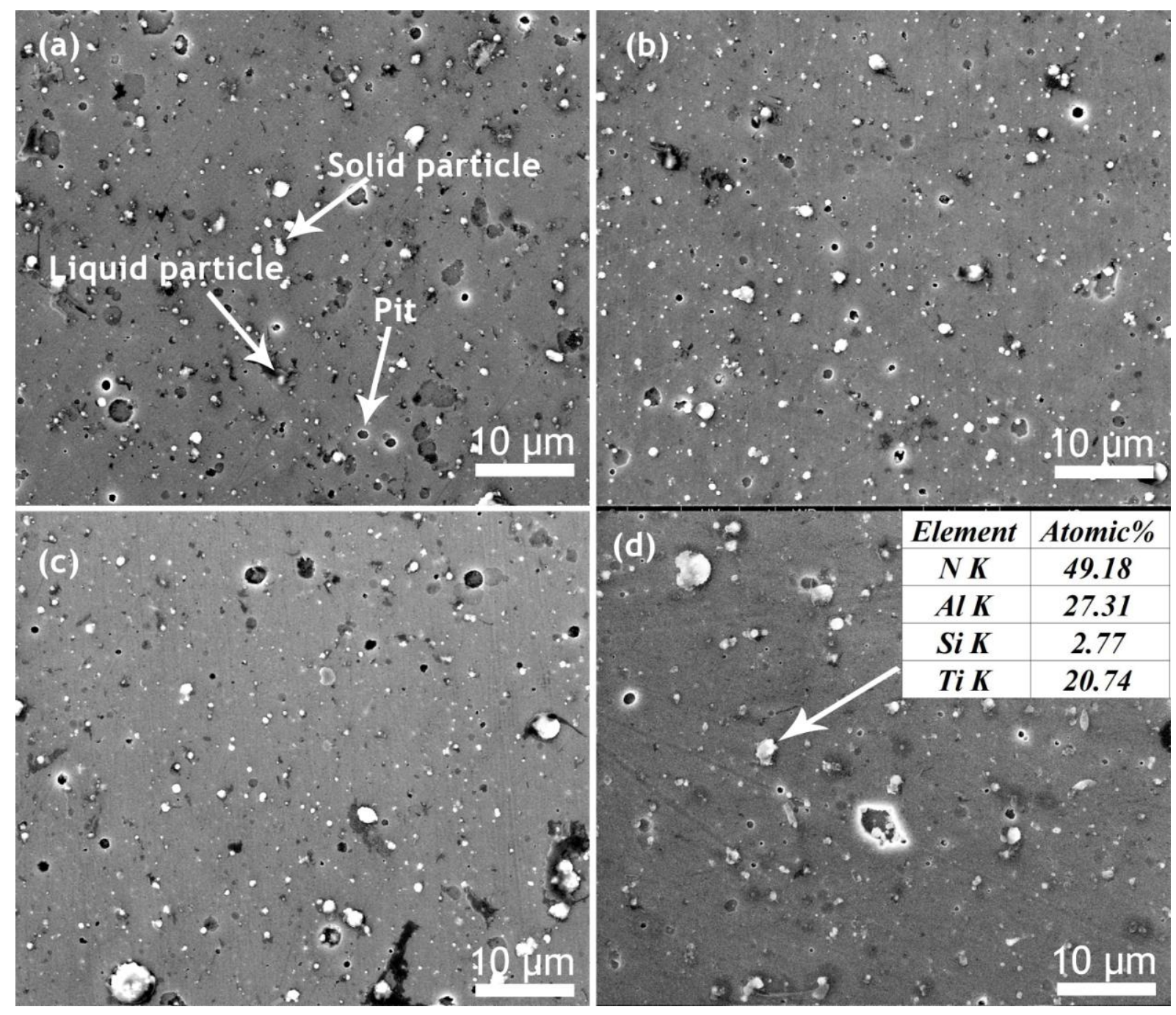



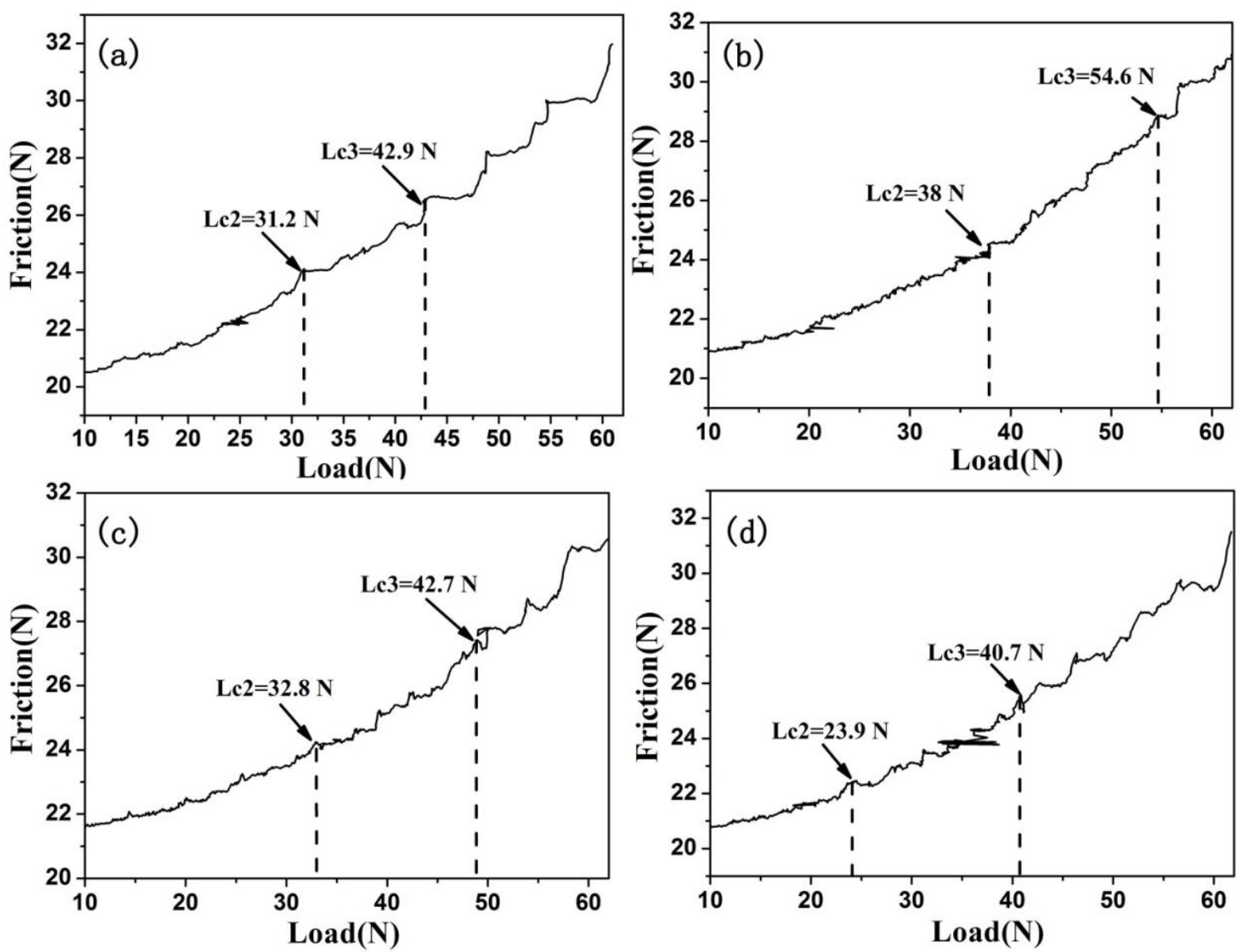


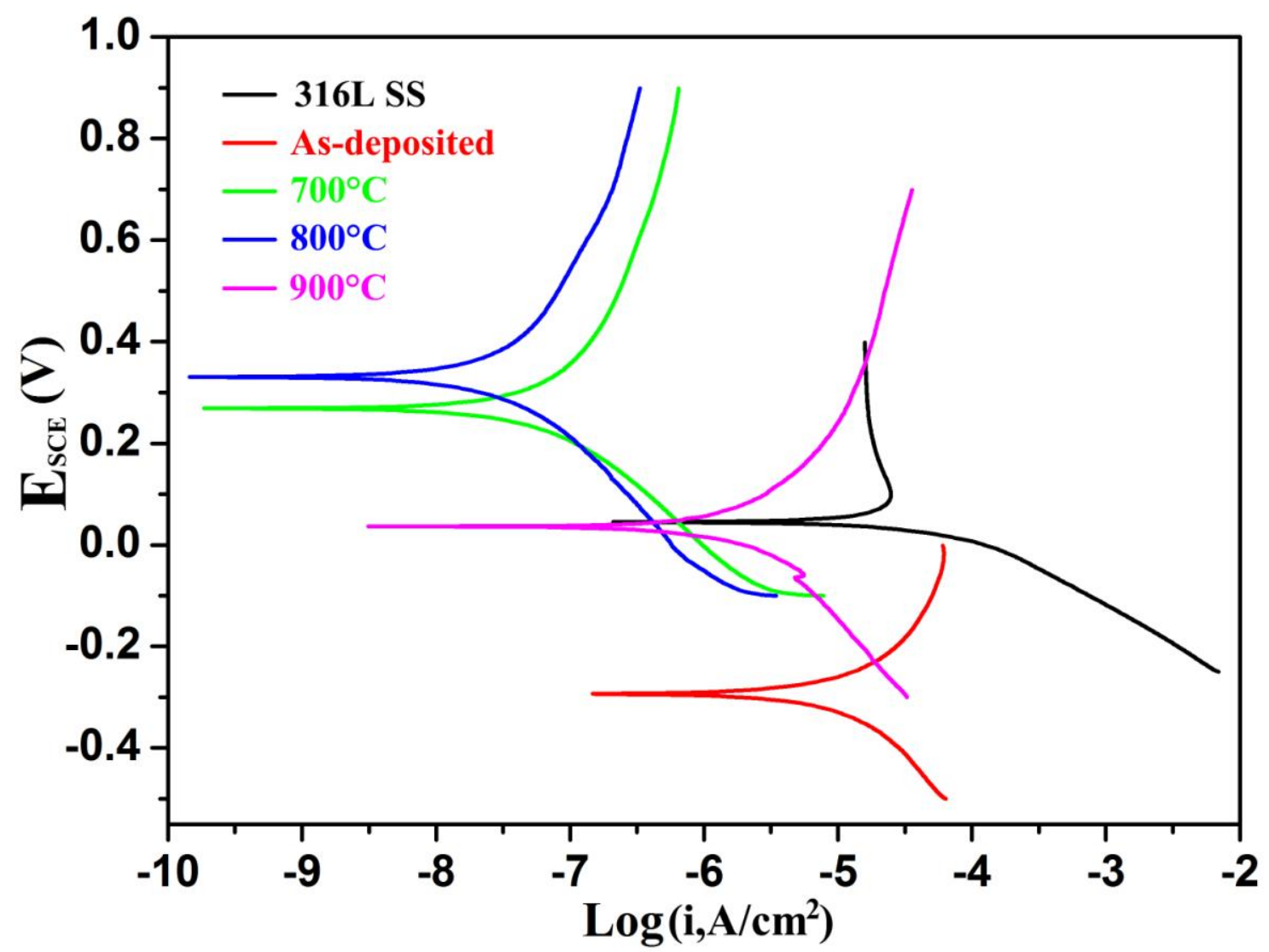


Table 1 Potentiodynamic polarization data of the 316L SS and Al-Ti-Si-N coatings before and after vacuum annealing in $10 \% \mathrm{H}_{2} \mathrm{SO}_{4}$ solution.

\begin{tabular}{cccccc}
\hline Samples & $\mathbf{E}_{\text {corr }}(\mathbf{V})$ & $\mathbf{i}_{\text {corr }}\left(\mathbf{A . c m}{ }^{-2}\right)$ & $\mathbf{R}_{\mathbf{p}}\left(\mathbf{\Omega . c m}{ }^{2}\right)$ & $\boldsymbol{\beta}_{\mathbf{c}}(\mathbf{V} / \mathbf{d e c})$ & $\mathbf{B}_{\mathbf{a}}(\mathbf{V} / \mathbf{d e c})$ \\
\hline $316 \mathrm{~L} \mathrm{SS}$ & 0.045 & $7.17 \times 10^{-5}$ & $6.85 \times 10^{2}$ & 7.309 & 1.545 \\
As-deposited & -0.293 & $1.30 \times 10^{-5}$ & $3.55 \times 10^{3}$ & 4.890 & 4.514 \\
$700^{\circ} \mathrm{C}$ & 0.269 & $5.57 \times 10^{-8}$ & $7.43 \times 10^{5}$ & 6.300 & 4.205 \\
$800^{\circ} \mathrm{C}$ & 0.331 & $2.79 \times 10^{-8}$ & $1.55 \times 10^{6}$ & 5.923 & 4.134 \\
$900^{\circ} \mathrm{C}$ & 0.036 & $2.63 \times 10^{-6}$ & $1.97 \times 10^{4}$ & 3.259 & 5.129 \\
\hline
\end{tabular}

